\title{
Metadata to the Cladocera (Crustacea: Branchiopoda) occurrences from Western Maharashtra, India
}

Sameer M. Padhye (iD, Roseline T. Thorat \& Avinash I. Vanjare (D)
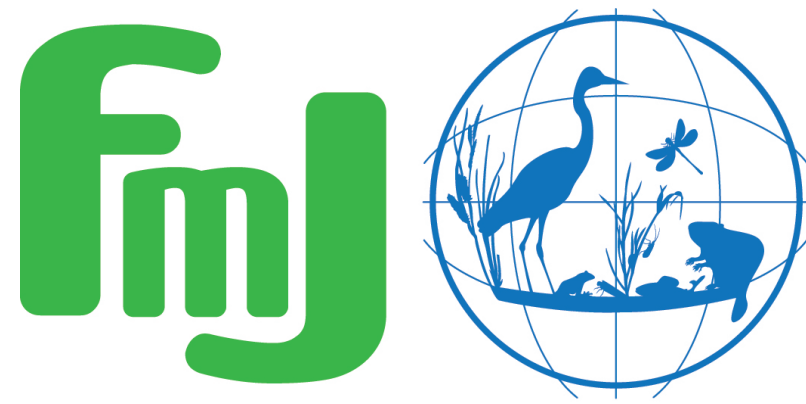

Freshwater Metadata Journal 



\title{
Metadata to the Cladocera (Crustacea: Branchiopoda) occurrences from Western Maharashtra, India
}

\author{
Sameer M. Padhye ${ }^{1}$ (iD , Roseline T. Thorat ${ }^{2} \&$ Avinash I. Vanjare ${ }^{2}$ iD \\ 1 Biologia Life Science LLP, Ahmednagar, India; corresponding author: sameer.m.padhye@gmail.com \\ 2 Department of Zoology, Ahmednagar College, Ahmednagar, India
}

Please cite this paper as follows: Padhye, S.M., Thorat, R.T. \& Vanjare, A.I., 2020. Metadata to the Cladocera (Crustacea: Branchiopoda) occurrences from Western Maharashtra, India. Freshwater Metadata Journal 50: 1-6. https://doi.org/10.15504/fmj.2020.50

Received: 2020-10-29 / Published: 2020-10-30

\section{Keywords}

Zooplankton, Anomopoda, Ctenopoda, Chydoridae, Daphnia, Moina, Alona

\section{Short description of the dataset/summary}

This dataset provides species distribution information on Cladocera, which is an important group of freshwater zooplankton from the Western region of Maharashtra state, India. The collection was carried out at over 100 distinct localities from the year 2009 until 2016. Multiple samples were collected at some of the localities. Most of the samples were collected qualitatively using either a tow net or a hand net having a mesh of 150 micrometers based on the type of habitat (open water vs. littoral zone). The dataset includes species names along with the GIS data and waterbody type (pool, pond, water reservoir or river). A total of 52 species were found from 7 different families. Chydoridae was the most species-rich family with 28 species (Padhye \& Dumont 2015, Padhye \& Sousa 2020). One new endemic species - Moina hemanti Padhye \& Dumont, 2014 - was newly described and another species - Magnospina siamensis (Sinev \& Sanoamuang, 2007) - was reported for the first time from the Indian subcontinent (Padhye \& Dumont 2014, Padhye \& Sousa 2020). The endemic species was restricted to its type locality. Daphnia carinata was only observed in lateritic rock pools, while species like Latonopsis australis were also seen in hot water springs (Padhye \& Kotov 2010, Padhye \& Victor 2015, Kulkarni et al. 2019).

\section{General information}

dataset entry ID:

name of the dataset:

full name of the dataset:

dataset short name:

type of dataset:

data type:
FWM_30

Cladocera (Crustacea: Branchiopoda) occurrences from Western Maharashtra, India

Cladocera from Maharashtra, India

species distribution data

point data/observation data 
science keywords according to GCMD:

topic: Biosphere, Terrestrial Hydrosphere

ISO topic category according to ISO 19115:

Biota, Inland Waters

INSPIRE keywords according to GEMET:

Species distribution

own science keywords: Zooplankton, Anomopoda, Ctenopoda, Chydoridae, Daphnia, Moina, Alona

funding:

Part of the work was carried out from the funds provided to SMP by the Council

of Scientific and Industrial Research (CSIR), India.

\section{Technical and administrative specifications}

$\begin{array}{ll}\text { data format: } & \text { Excel } \\ \text { operating system: } & \text { others/specify } \\ \text { others/details: } & \text { Windows } 10 \\ \text { data language: } & \text { English } \\ \text { current access level: } & \text { restricted access } \\ \quad \text { currently available through GBIF: } & \text { no } \\ \text { exchange planned: } & \text { yes } \\ \text { data in data repository: } & \text { no }\end{array}$

Do you plan to publish the data on the Freshwater Biodiversity Data Portal:

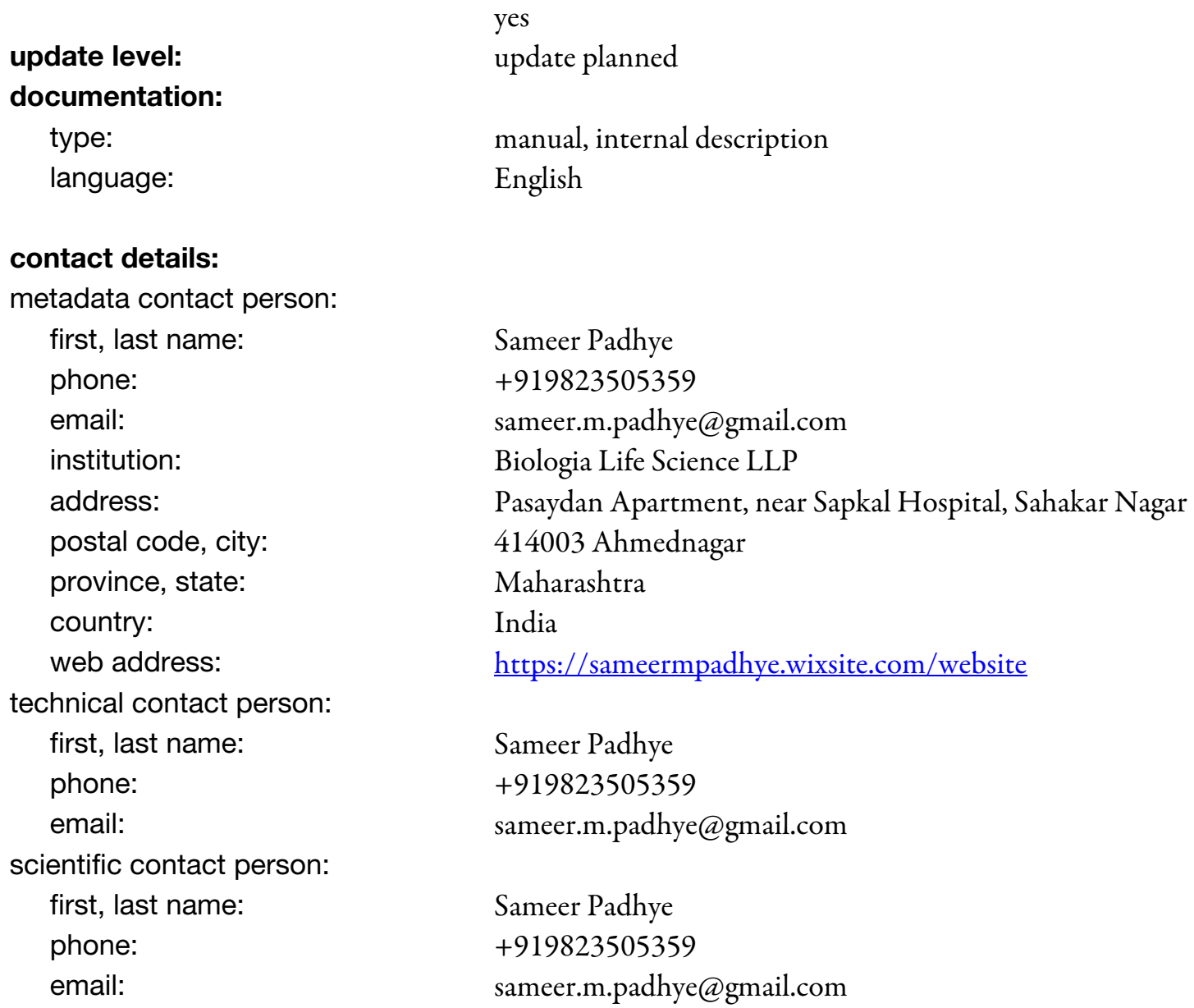




\section{Intellectual property rights and citation}

dataset creator (data compiler):

contact name:

Sameer M. Padhye

contact email:

sameer.m.padhye@gmail.com

contact institution:

Biologia Life Science LLP

\section{data contributors to/owners of this dataset:}

multiple

number:

3

\section{data contributor/owner 1:}

contact name:

contact email:

contact institute:

sameer.m.padhye@gmail.com

Biologia Life Science LLP

criteria for using this part of the dataset:

The dataset is publicly available (data portal, data archive) and can be used without restrictions, but dataset creator/data contributors must be informed prior to publication. Data must be acknowledged and cited correctly.

data contributor/owner 2:

contact name:

contact email:

roseline.thorat@gmail.com

contact institute:

Department of Zoology, Ahmednagar College, Station road, Ahmednagar,

Maharashtra

criteria for using this part of the dataset:

The dataset is publicly available (data portal, data archive) and can be used without restrictions, but dataset creator/data contributors must be informed prior to publication. Data must be acknowledged and cited correctly.

data contributor/owner 3:

contact name:

contact email:

avinashisaac7@gmail.com

contact institute:

Department of Zoology, Ahmednagar College, Station road, Ahmednagar,

Maharashtra

criteria for using this part of the dataset:

The dataset is publicly available (data portal, data archive) and can be used without restrictions, but dataset creator/data contributors must be informed prior to publication. Data must be acknowledged and cited correctly.

citation of this dataset:

author(s):

Padhye, S.M., Thorat, R. \& Vanjare, A.I.

title and journal (name, number, pages):

Cladocera (Crustacea: Branchiopoda) occurrences from Western Maharashtra,

India

year: $\quad 2020$

\section{citation of the metadata:}

author(s):

Padhye, S.M., Thorat, R.T. \& Vanjare, A.I.

title and journal (name, number, pages):

Metadata to the Cladocera (Crustacea: Branchiopoda) occurrences from

Western Maharashtra, India. Freshwater Metadata Journal 50: 1-6

year:

2020

doi:

https://doi.org/10.15504/fmj.2020.50

\section{dataset related references:}

reference 1:

author(s):

Padhye, S. \& Dumont, H.J. 
title:

year:

doi:

reference 2:

author(s):

title:

year:

doi:

reference 3:

author(s):

title:

year:

doi:

reference 4:

author(s):

title:

year:

doi:

reference 5 :

author(s):

title:

year:

doi:

reference 6:

author(s):

title:

year:

doi:

reference 7:

author(s):

title:

year:

doi:

reference 8:

author(s):

title:

year:

doi:
Moina hemanti n. sp., a new species of the genus Moina s.l. (Branchiopoda: Anomopoda) from Pune, India. Zootaxa 3860(6): 561-570.

2014

http://dx.doi.org/10.11646/zootaxa.3860.6.4

Padhye, S. \& Dumont, H.J.

Species richness of Cladocera (Crustacea: Branchiopoda) in the Western Ghats of Maharashtra and Goa, India with biogeographical comments. Journal of Limnology 74(1): 182-191.

2015

https://doi.org/10.4081/jlimnol.2014.1033

Padhye, S.M. \& Van Damme, K.

Note on Kurzia (Kurzia) latissima (Kurz, 1875) (Branchiopoda: Anomopoda: Chydoridae) from India. Zootaxa 3980(2): 293-297.

2015

http://dx.doi.org/10.11646/zootaxa.3980.2.10

Padhye, S.M. \& Victor, R.

Diversity and distribution of Cladocera (Crustacea: Branchiopoda) in the rock pools of Western Ghats, Maharashtra, India. Annales de Limnolgie 51: 315-322. 2015

https://doi.org/10.1051/limn/2015029

Padhye, S.M., Kotov, A.A., Dahanukar, N. \& Dumont, H.J.

Biogeography of the 'water flea' Daphnia (Crustacea: Branchiopoda:

Anomopoda) in the Indian subcontinent. Journal of Limnology 75(3): 571-580. 2016

https://doi.org/10.4081/jlimnol.2016.1476

Kulkarni, M.R., Padhye, S.M., Rathod, R.B., Shinde, Y.S. \& Pai, K.

Hydroperiod and inter-pool distance influence meta-community composition of crustaceans in temporary rock-pools in India. Inland Waters 9(3): 320-333.

2019

https://doi.org/10.1080/20442041.2018.1548868

Padhye, S.M.

Seasonal variation in functional composition and diversity of cladoceran zooplankton of a lotic eutrophic habitat from India. Annales de Limnologie 56, 11.

2020

https://doi.org/10.1051/limn/2020011

Sousa, F.D.R. \& Padhye, S.M.

First record of the dentifera-group of Aloninae (Cladocera, Chydoridae) from tropical India. Zootaxa 4802(2): 391-394.

2020

https://doi.org/10.11646/zootaxa.4802.2.12 


\section{General data specifications}

regional coverage of the dataset:

continents:

countries:

comments:
Asia

Asia: India

The dataset is from the state of Maharashtra in India.

\section{world climatic regions according to Köppen:}

Group A: tropical/megathermal climates

Group B: dry (arid and semiarid) climates

freshwater ecoregions of the world (FEOW) according to WWF:

ecosystem type:

covered timeframe:

\section{Site specifications}

coordinate system/grid data:

grid data available:

comments:

number of sites:

exact number of sites:

\section{Biological data}

biological data origin:

organism group addressed:
Asia: Northern Deccan Plateau, Western Ghats rivers, lakes/ponds, wetlands, general freshwater $2009-2016$ latitude/longitude, format: DD

no

Some of the sites were distributed over a very small region like a rocky outcrop, where obtaining separate GIS data of pools was not possible. Hence, GIS data is redundant in such instances.

$100-1000$

130

\section{Sample resolution}

\section{zooplankton:}

taxonomic resolution:

level:

genus, species

percentage of species level data: 100

\section{taxonomic coding:}

taxalist according to:

Chatterjee et al. (2013)

reference(s):

from sampling,

Diversity of Cladocera (Crustacea: Branchiopoda) in the Northern Western Ghats

zooplankton (Cladocera)

\section{sample specifications:}

Chatterjee, T., Kotov, A.A., Van Damme, K., Chandrasekhar, S.V.A., \& Padhye, S. (2013). An annotated checklist of the Cladocera (Crustacea: Branchiopoda) from India. Zootaxa 3667(1): 1-89.

specification of method(s) used for sampling and sorting:

Qualitative sampling was carried out using either a tow net or a hand net based on the type of habitat (pool vs. river) or exact region of sampling (open water vs. littoral region). The mesh size of the nets was 150 micrometers. The samples were preserved in $5-8 \%$ formalin in the field. 


\section{Other specifications}

GIS layers, shape files related to the dataset:

\begin{tabular}{ll} 
availability of photos: & no data available \\
availability of maps: & no \\
quality control procedures: & no \\
\multicolumn{2}{c}{ Were any quality control procedures applied to your dataset? }
\end{tabular}

no

\section{Acknowledgements}

SMP thanks the Director, Biologia Life Science LLP for the support. RT and AIV thank the Principal, Ahmednagar College, Ahmednagar for support. All the authors thank Mihir R. Kulkarni, Yughandhar Shinde, Shruti Paripatyadar, Sayali Sheth, Siddharth Kulkarni, Samadhan Phuge \& Nikhil Modak for their help and support during the fieldwork. SMP thanks Hemant Ghate for his support.

\section{References}

Kulkarni, M.R., Padhye, S.M., Rathod, R.B., Shinde, Y.S. \& Pai, K., 2019. Hydroperiod and inter-pool distance influence meta-community composition of crustaceans in temporary rock-pools in India. Inland Waters 9(3): 320-333. https://doi.org/10.1080/20442041.2018.1548868

Padhye, S. \& Dumont, H.J., 2014. Moina hemanti n. sp., a new species of the genus Moina s.l. (Branchiopoda: Anomopoda) from Pune, India. Zootaxa 3860(6): 561-570. https://doi.org/10.11646/zootaxa.3860.6.4

Padhye, S. \& Dumont, H.J., 2015. Species richness of Cladocera (Crustacea: Branchiopoda) in the Western Ghats of Maharashtra and Goa, India with biogeographical comments. Journal of Limnology 74(1): 182-191.

https://doi.org/10.4081/jlimnol.2014.1033

Padhye, S.M., 2020. Seasonal variation in functional composition and diversity of cladoceran zooplankton of a lotic eutrophic habitat from India. Annales de Limnologie 56, 11. https://doi.org/10.1051/limn/2020011

Padhye, S.M. \& Van Damme, K., 2015. Note on Kurzia (Kurzia) latissima (Kurz, 1875) (Branchiopoda: Anomopoda: Chydoridae) from India. Zootaxa 3980(2): 293-297. https://doi.org/10.11646/zootaxa.3980.2.10

Padhye, S.M. \& Victor, R., 2015. Diversity and distribution of Cladocera (Crustacea: Branchiopoda) in the rock pools of Western Ghats, Maharashtra, India. Annales de Limnolgie 51: 315-322. https://doi.org/10.1051/limn/2015029

Padhye, S.M., Kotov, A.A., Dahanukar, N. \& Dumont, H.J. , 2016. Biogeography of the 'water flea' Daphnia (Crustacea: Branchiopoda: Anomopoda) in the Indian subcontinent. Journal of Limnology 75(3): 571-580.

https://doi.org/10.4081/jlimnol.2016.1476

Sousa, F.D.R. \& Padhye, S.M., 2020. First record of the dentifera-group of Aloninae (Cladocera, Chydoridae) from tropical India. Zootaxa 4802(2): 391-394. https://doi.org/10.11646/zootaxa.4802.2.12 